\title{
ANN Current Controller Based on PI-Fuzzy Adaptive System for Shunt Power Active Filter
}

\author{
Moulay Tahar Lamchich \\ Department of Physics, Faculty of Sciences Semlalia, Cadi Ayyad University, 40000 Marrakech, Morocco \\ Correspondence should be addressed to M. T. Lamchich, lamchich@ucam.ac.ma
}

Received 14 December 2011; Revised 17 July 2012; Accepted 17 July 2012

Academic Editor: Jose Pomilio

Copyright () 2012 M. T. Lamchich. This is an open access article distributed under the Creative Commons Attribution License, which permits unrestricted use, distribution, and reproduction in any medium, provided the original work is properly cited.

This paper deals with the use of triphase shunt active filter which is able to compensate current harmonics, reactive power, and current unbalance produced by nonlinear loads. To perform the identification of disturbing currents, a very simple control method is introduced. It's formed by a DC voltage regulator and a balance between the average power of load and the active power supplied by the grid. The output current of the voltage source inverter (VSI) must track the reference current. This is done by a neural controller based on a PI-Fuzzy adaptive system as reference corrector. Also to regulate the DC link capacitor voltage a fuzzy logic adaptive PI controller is used.

\section{Introduction}

Due to the increased use of nonlinear electrical loads, such as power electronics supplies, harmonics currents are generated in the level of these loads and injected back to the grid causing its voltage distortion at harmonics currents' frequencies. The distorted voltage generates distorted currents which will be absorbed by sensitive loads and causing losses in the lines. Also, the most consuming electrical power loads are almost inductive, and then they contribute to the degradation of grid power factor at the point of common connection (PCC).

Conventionally, passive filters were adopted for the reduction of harmonics and to improve power factor; therefore, they have the disadvantages such as fixed frequency compensation, resonance, and large size. These limitations were avoided by the use of active filters which utilized a switch-mode power electronic converter to supply harmonic currents equal to those in the load currents.

The main objective of the power active filter (PAF) is to compensate reactive power, current harmonics, neutral current, and unbalancing of nonlinear loads by injecting compensating currents.

Almost, the method-based instantaneous active and reactive power (pq method) [1] is currently performed for disturbing current identification. The major disadvantages of a bloc identification-based pq method are essentially as follows:

(i) it is not effective under distorted and unbalanced mains voltages conditions;

(ii) the time delays introduced by pass filters, which are used to separate the average and oscillating parts of powers, degrades the dynamic performance of active filter;

(iii) this method requires more computational calculation.

The controller of the PAF is comprised of an inner current loop which actively shapes the line currents and an outer voltage control loop which regulates the magnitude of the line currents.

This paper presents the application of a fuzzy inference system to determine the parameters of a PI controller used for the DC voltage regulation.

The current loop uses a technique-based artificial neural networks (ANN). The PI-Fuzzy adaptive system is adopted, as reference corrector, for the process learning.

The simulation results, in power system blockset (PSB) Matlab/Simulink environment, will show the effectiveness of the proposed approach for the control of the power active filter. 


\section{General Structure}

The main circuit of the shunt active filter control, as used in the Matlab/Simulink environment, is shown by Figure 1. It is composed of

(i) a three wires power network and the output filter;

(ii) the nonlinear load based on a rectifier;

(iii) a reference current identification bloc based on a balance between powers;

(iv) two regulation blocs, of capacitor voltage and the inverter, based on a neurofuzzy logic technique;

(v) the active filter consisting of a voltage source inverter (VSI) with a capacitor in its DC side.

\section{Disturbing Current Identification}

The compensation of the current harmonics and reactive power, generated by the nonlinear load, has an object to impose that the AC source currents must be sinusoidal and in phase with source voltages.

So the power active filter (PAF), used as a controlled current source, is controlled by determining its reference currents to inject the compensating currents.

The purpose of it is to produce output currents for tracking the reference current in order to reduce the harmonic components and compensate the reactive power.

We can proceed as follows to determine the reference currents for the control of the PAF:

(i) we start by determining the reference grid currents (noted $i_{s j}^{*} ; j=a, b, c$ ) witch realized these two conditions (sinusoidal form with unit power factor).

(ii) the inverter reference currents (noted $i_{o j}^{*} ; j=a, b, c$ ), which permit the PAF control, are deduced from the following equation:

$$
i_{o j}^{*}=i_{c j}-i_{s j}^{*} ; \quad j=a, b, c,
$$

where $i_{c j} ; j=a, b, c$ are the load currents.

(iii) as show in Figure 1, we evaluate the maximal value (noted IREF) of the reference grid currents, and we use a PLL circuit to generate the sinusoidal forms from the source voltages.

(iv) the maximal value IREF can be deduced from a balance between active power supplied by the AC source and fundamental active power component absorbed by nonlinear load plus losses of inverter for regulating the DC capacitor voltage.

Therefore, The peak of source reference current (IREF) has two components; the first one $\left(I_{\mathrm{sA}}^{*}\right)$ is corresponding to the average load active power, and the second one $\left(I_{\mathrm{sD}}^{*}\right)$ is obtained from the DC capacitor voltage regulation as follows [2]:

$$
\mathrm{IREF}=I_{\mathrm{sA}}^{*}+I_{\mathrm{SD}}^{*}
$$

The average power of load is obtained using a low-pass filter as shown by Figure 2 .

By considering the unity power factor for grid currents, the component $I_{\mathrm{sA}}^{*}$ is defined as follows:

$$
I_{\mathrm{sA}}^{*}=\frac{2}{3} \frac{P_{\mathrm{Lav}}}{V_{\mathrm{sm}}},
$$

where $V_{\text {sm }}$ is the peak voltage of AC source.

The second component of AC source current $I_{\mathrm{sD}}^{*}$ is obtained from the DC capacitor voltage regulation as shown by Figure 3 .

We can also justify this procedure, for the determination of the reference current, by calculation of instantaneous power components of the $p$ - $q$ theory in a stationary $\alpha \beta$-frame [3].

The load absorbed the instantaneous active power as follows:

$$
p_{l}=v_{1} i_{1}+v_{2} i_{2}+v_{3} i_{3}=v_{\alpha} i_{\alpha}+v_{\beta} i_{\beta} .
$$

This power may be decomposed into oscillating component called harmonic power $\left(\tilde{p}_{l}\right)$ and average component called fundamental $\left(\bar{p}_{l}\right)$.

For generation of the reference current, a balance between instantaneous powers supplied by the source (noted $\left.p_{s}\right)$ and the PAF $\left(p_{f}\right)$ and drained by the load is to be computed.

For obtaining inphase current with supply voltage, the harmonic term of instantaneous active power and all terms of instantaneous reactive power should be removed. In this case, balance of power yields as follows:

$$
p_{s}=\bar{p}_{l} \quad p_{f=} p_{l-} p_{s=} \tilde{p}_{l} .
$$

In normal operating condition, the PAF should be able to supply $p_{f}=\tilde{p}_{l}$, and consequently voltage level of capacitor remains constant for duration of steady state while it varies during period of transient. In order to control capacitor voltage level on the DC side of the inverter is essential to adjust previous equation.

\section{DC-Bus Voltage Control}

The DC link voltage control is performed to define the second component of AC source current $I_{\mathrm{sD}}^{*}$ (or harmonic power generated by the PAF) as described below.

In this paper, a PI controller, which its parameters are adjusted by a fuzzy inference system, is used to regulate the DC link voltage [4]. This technique, which consists of gains variation during the system control, takes the PI controller adaptable to nonlinear system and its parameters variation.

The principle scheme of this technique is illustrated by Figure 3.

The PI parameters $\left(K_{p}, K_{i}\right)$ are calculated using the intermediate values $\left(K_{p}^{\prime}, K_{i}^{\prime}\right)$, given by the fuzzy controller, as follows [5]:

$$
\begin{aligned}
K_{p} & =\left(K_{p_{\max }}-K_{p_{\min }}\right) K_{p}^{\prime}+K_{p_{\min }}, \\
K_{i} & =\left(K_{i_{\max }}-K_{i_{\min }}\right) K_{i}^{\prime}+K_{i_{\min }},
\end{aligned}
$$




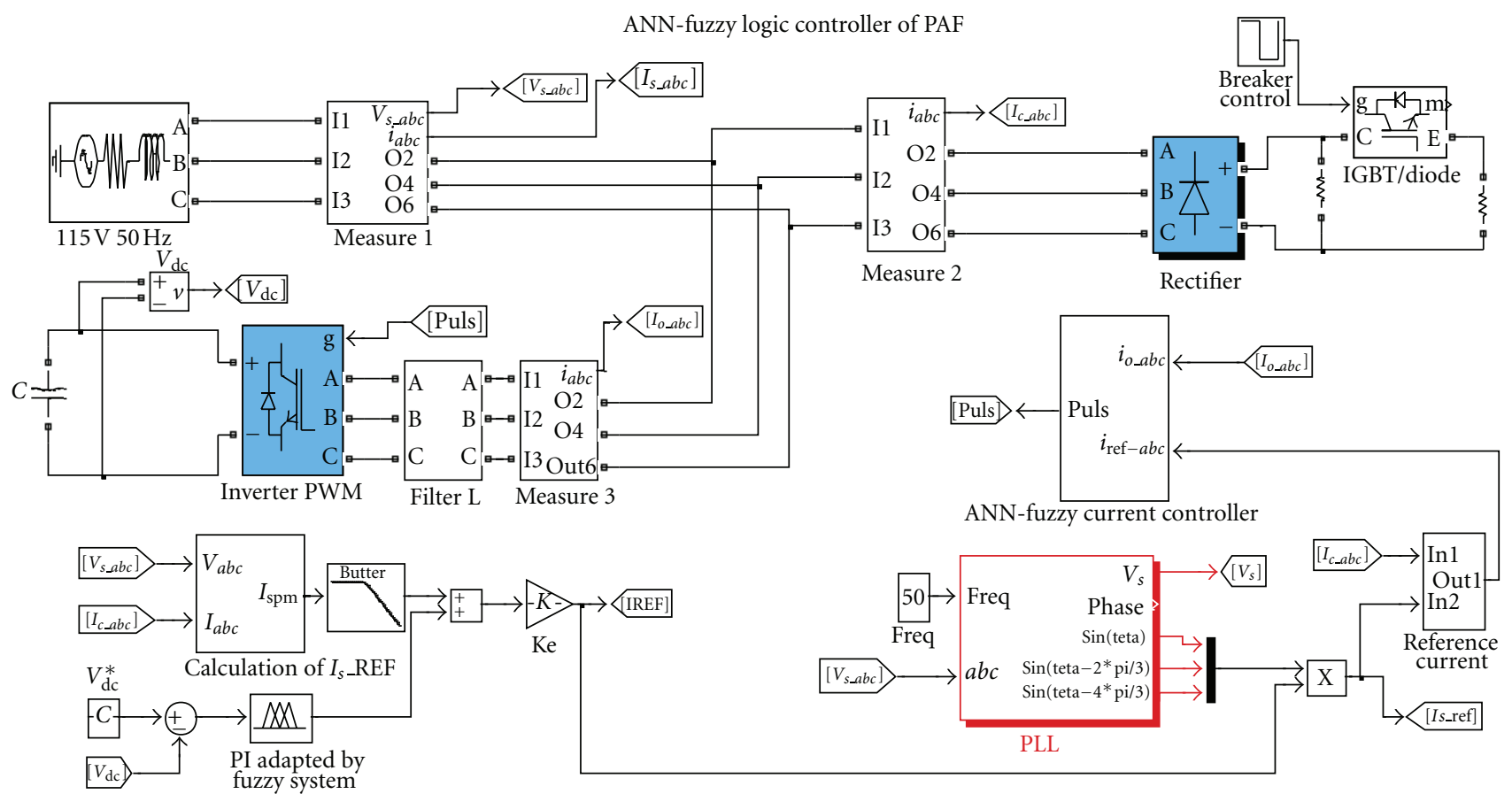

FIGURE 1: General structure of the PFA control.

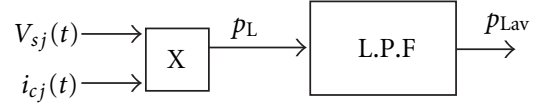

Figure 2: Calculation of the average power of load.

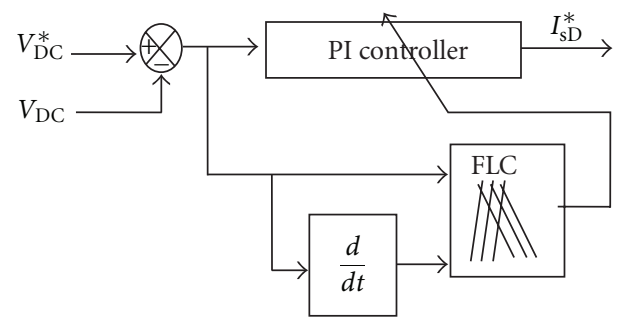

FIGURE 3: VDC regulation with PI adapted by Fuzzy inference system.

where the extremes values of the gains are defined from the parameters given by Ziegler-Nichols method.

Both quantities $\left(K_{p}^{\prime}, K_{i}^{\prime}\right)$, corresponding to the output of the fuzzy system (Figure 4), are normalized in the range $\left[\begin{array}{ll}0 & 1\end{array}\right]$.

The membership functions are chosen the same, respectively, for the error and the slope and for the parameters $K_{p}^{\prime}$ and $K_{i}^{\prime}$ (Figures 5 and 6).

We have chosen to characterize this fuzzy controller by seven sets, respectively, for the inputs and only two sets for the outputs.

The linguistic rules, for the fuzzy logic output variables $K_{p}^{\prime}$ and $K_{i}^{\prime}[6]$, are resumed in the Table 1 .

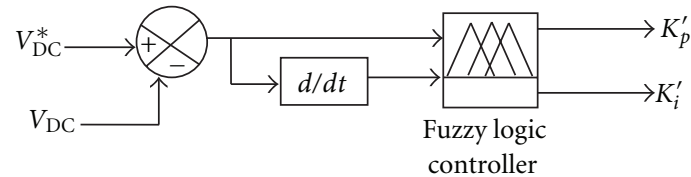

Figure 4: $K_{p}^{\prime}$ and $K_{i}^{\prime}$ evaluated by Fuzzy system.

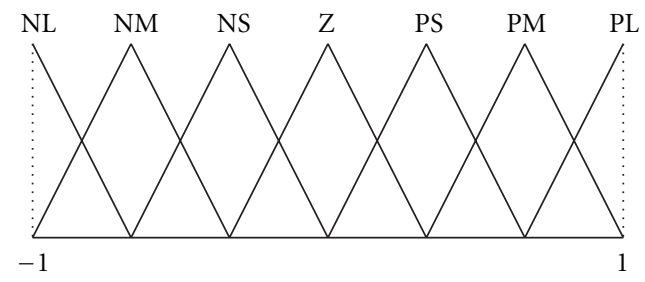

FIGURE 5: Membership function for the error and slope.

\section{ANN Current Control}

To obtain the desired switching signals according to either output inverter currents or grid currents to follow the reference ones, a technique-based artificial neural network has been introduced.

Neural networks, which have the potential to provide an improved method of deriving nonlinear models, have self adapting capabilities which make them well suitable to handle nonlinearities, uncertainties, and parameter variations.

In the last years, a big interest concerned the use of the artificial intelligence techniques (neural networks, fuzzy logic, genetic algorithms) in identification and nonlinear 


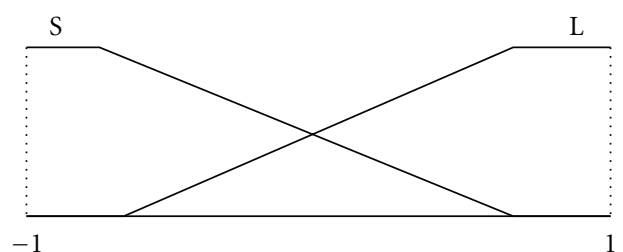

Figure 6: Membership function for the parameters $K_{p}^{\prime}$ and $K_{i}^{\prime}$.

TABLE 1: Fuzzy rules for the outputs $K_{p}^{\prime}$ and $K_{i}^{\prime}$.

\begin{tabular}{llllcccc}
\hline \multirow{2}{*}{ Slope } & & \multicolumn{7}{c}{ Error } \\
& NL & NM & NS & Z & PS & PM & PL \\
\hline NL & $\mathrm{L} / \mathrm{L}$ & $\mathrm{L} / \mathrm{L}$ & $\mathrm{L} / \mathrm{L}$ & $\mathrm{L} / \mathrm{L}$ & $\mathrm{L} / \mathrm{L}$ & $\mathrm{L} / \mathrm{L}$ & $\mathrm{L} / \mathrm{L}$ \\
$\mathrm{NM}$ & $\mathrm{S} / \mathrm{L}$ & $\mathrm{L} / \mathrm{L}$ & $\mathrm{L} / \mathrm{S}$ & $\mathrm{L} / \mathrm{S}$ & $\mathrm{L} / \mathrm{S}$ & $\mathrm{L} / \mathrm{L}$ & $\mathrm{S} / \mathrm{L}$ \\
$\mathrm{NS}$ & $\mathrm{S} / \mathrm{L}$ & $\mathrm{S} / \mathrm{L}$ & $\mathrm{L} / \mathrm{L}$ & $\mathrm{L} / \mathrm{S}$ & $\mathrm{L} / \mathrm{L}$ & $\mathrm{S} / \mathrm{L}$ & $\mathrm{S} / \mathrm{L}$ \\
$\mathrm{Z}$ & $\mathrm{S} / \mathrm{L}$ & $\mathrm{S} / \mathrm{L}$ & $\mathrm{S} / \mathrm{L}$ & $\mathrm{L} / \mathrm{S}$ & $\mathrm{S} / \mathrm{L}$ & $\mathrm{S} / \mathrm{L}$ & $\mathrm{S} / \mathrm{L}$ \\
$\mathrm{PS}$ & $\mathrm{S} / \mathrm{L}$ & $\mathrm{S} / \mathrm{L}$ & $\mathrm{L} / \mathrm{L}$ & $\mathrm{L} / \mathrm{S}$ & $\mathrm{L} / \mathrm{L}$ & $\mathrm{S} / \mathrm{L}$ & $\mathrm{S} / \mathrm{L}$ \\
$\mathrm{PM}$ & $\mathrm{S} / \mathrm{L}$ & $\mathrm{L} / \mathrm{L}$ & $\mathrm{L} / \mathrm{S}$ & $\mathrm{L} / \mathrm{S}$ & $\mathrm{L} / \mathrm{S}$ & $\mathrm{L} / \mathrm{L}$ & $\mathrm{S} / \mathrm{L}$ \\
$\mathrm{PL}$ & $\mathrm{L} / \mathrm{L}$ & $\mathrm{L} / \mathrm{L}$ & $\mathrm{L} / \mathrm{L}$ & $\mathrm{L} / \mathrm{L}$ & $\mathrm{L} / \mathrm{L}$ & $\mathrm{L} / \mathrm{L}$ & $\mathrm{L} / \mathrm{L}$ \\
\hline
\end{tabular}

control systems, this is mainly due to their capacities of learning and generalization [7-9].

In this object, the present work consists, partially, in developing a neural corrector for the control of the active power filter currents.

In this control system, we developed a neural controller by learning the behavior of a reference corrector. To do this, we have chosen, as reference corrector, a PI-Fuzzy adaptive system, which has good performances and could be able to adapt to changes in load.

The learning structure of this PI-Fuzzy corrector is given by Figure 7 .

The ANN is a three-layer network: the first layer has four nodes, the hidden layer has three neurons, and the output layer has only one neuron corresponding to the inverter switching signal.

As mentioned below, the PI-Fuzzy reference corrector is used for the phase of learning, allowing to determine the parameters of this neural corrector and particularly its weights.

The learning procedure used was the Levenberg Marquardt backpropagation algorithm. The weights are generated until the error between the calculated pattern and the desired pattern, corresponding to the output of the fuzzy system as reference model, is very small and acceptable.

After this stage, the weights final values, corresponding to the steady state of the PAF control, are saved and applied, in the second phase, steadily to the neural controller (Figure 8).

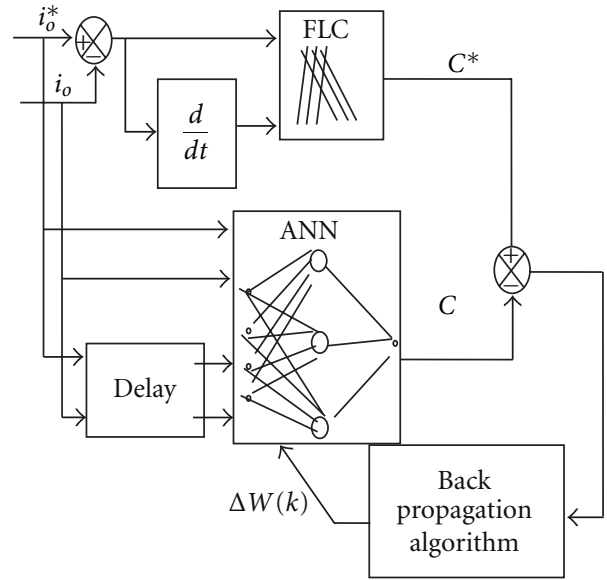

FIGURE 7: Learning scheme of the ANN for generating the inverter switching control.

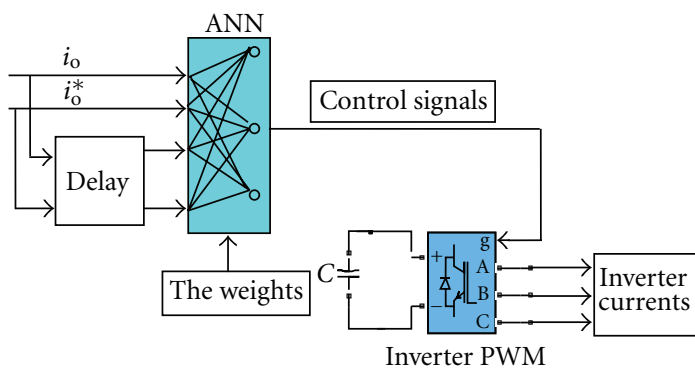

FIGURE 8: ANN corrector developed for the PAF control.

Approximations of ANN weights values, for one phase of inverter, are given as follows

$$
\left[\begin{array}{c}
W_{11}=4.20 \\
W_{12}=2.45 \\
W_{13}=-0.3 \\
W_{14}=1.85 \\
W_{k 1}=-0.28
\end{array}\right]\left[\begin{array}{c}
W_{21}=7.10 \\
W_{22}=-3.55 \\
W_{23}=0.07 \\
W_{24}=-3.3 \\
W_{k 2}=0.55
\end{array}\right]\left[\begin{array}{c}
W_{31}=4.20 \\
W_{32}=2.45 \\
W_{33}=-0.3 \\
W_{34}=1.85 \\
W_{k 3}=-0.28
\end{array}\right] .
$$

These weights are applied to the neural controller without the fuzzy system used only as reference corrector for the learning state.

\section{Simulation Results}

Simulations were performed to show the effectiveness of the PAF regulation by means of PI-Fuzzy adaptive corrector for the DC link voltage control and by the use of ANN corrector for the PAF current control.

A nonlinear load, consisting of a three-phase diode-based rectifier and a resistive load in its DC side, is fed by sinusoidal and symmetrical mains phase voltages $(127 \mathrm{Vrms}, 50 \mathrm{~Hz})$.

Figures 9 and 10 show the load current without compensation (only one phase current is represented for the clearness) and its harmonics spectrum, respectively. It is clearly shown that the total harmonic distortion (THD) is relatively high (the calculated value is approximately $22 \%$ ). 


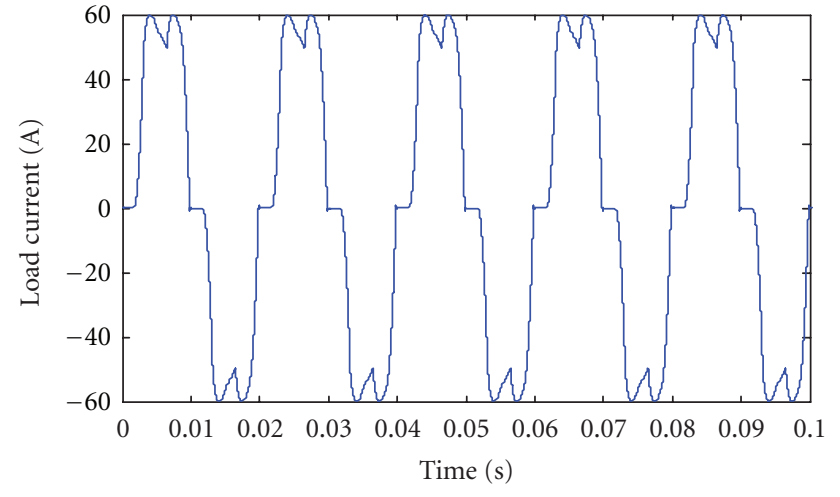

FIGURE 9: Load current before compensation.

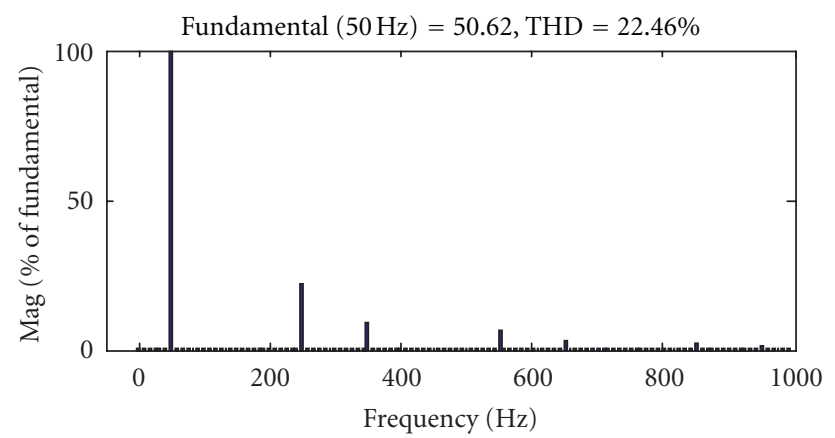

FIGURE 10: Load current spectrum before compensation.

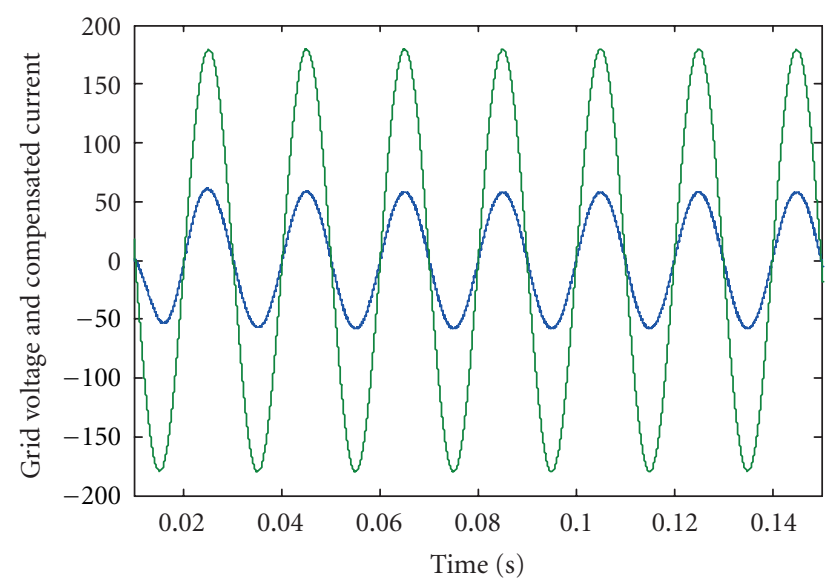

FIGURE 11: Source voltage and compensated current.

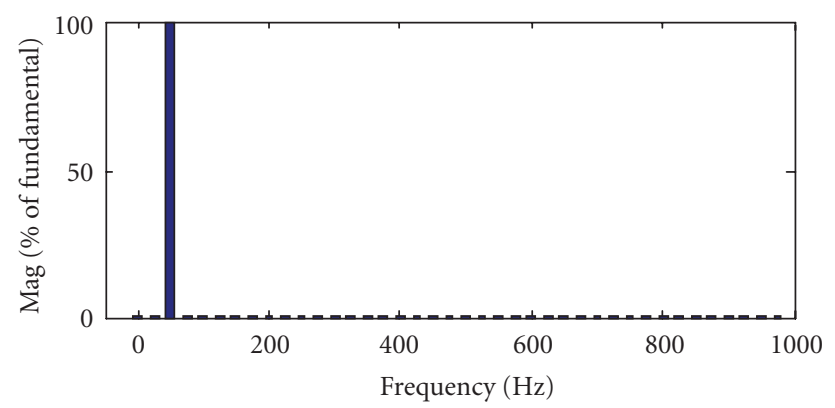

FIGURE 12: Grid current spectrum after compensation.

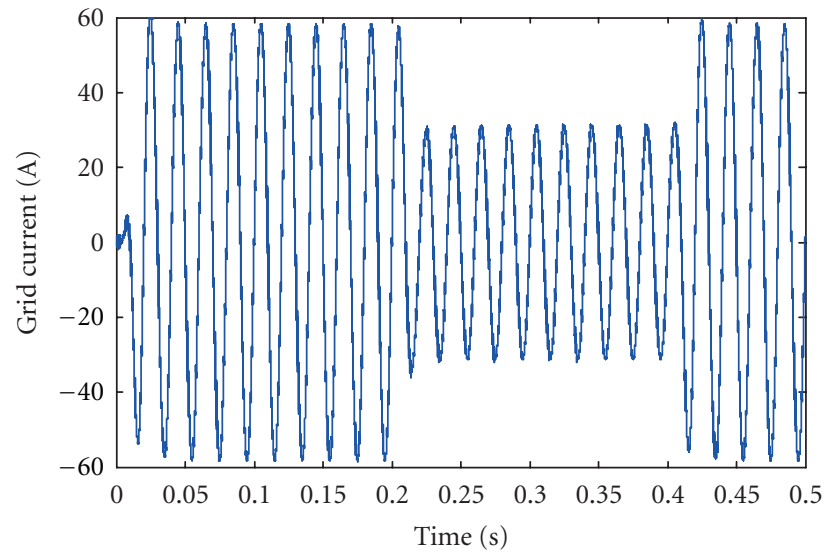

Figure 13: Grid current transient response.

The simulation results of the proposed control algorithm are presented in the next figures. Thus, Figure 11 shows that the source current becomes closely sinusoidal and inphase with source voltage. The source power factor is near unity, and the THD is enormously reduced (the harmonics spectrum, as represented in Figure 12, is reduced to only the fundamental and the calculated value of THD which is approximately $1.2 \%$ ).

To show the dynamics of the proposed control algorithm, a step change is made in the load. The result is presented in Figure 13. It is obviously shown that the transient response time is very short, and so the dynamic of the controlled system is high.

\section{Conclusion}

The shunt power active filter (PAF) is basically used to compensate harmonics, produced in the case of a nonlinear load, and reactive power. In this paper, we have presented the simulation results, using the Matlab/Simulink PSB Blocs, for the PAF control.

The reference current's identification is accomplished by an approach based on a powers balance between the active power provided by AC source and that absorbed by the load.

The DC voltage regulation is done by using a PI-Fuzzy adaptive controller. The output current is then used for the currents reference's identification.

To control the PAF, a neurofuzzy controller is adopted, with a PI-Fuzzy system as a reference corrector for the learning stage, and which imposes the generated current to track closely the reference current.

The first investigations, presented here, of the control algorithm prove its effectiveness and its high dynamics. It will be completed in a future work by using other artificial techniques and by considering others PAF configurations.

\section{References}

[1] H. Akagi, Y. Kanazawa, and A. Nabae, "Instantaneous reactive power compensators comprising switching devices without energy storage components," IEEE Transactions on Industry Applications, vol. IA-20, no. 3, pp. 625-630, 1984. 
[2] A. Jami and S. H. Hosseini, "Implementation of a novel control strategy for shunt active filter," The ECTI Transactions on Electrical Engineering, Electronics, and Communications, vol. 4, no. 1, pp. 40-46, 2006.

[3] H. Akagi, Y. Kanazawa, and A. Nabae, "Generalized theory of the instantaneous reactive power in three-phase circuits," pp. 1375-1386, International Power Electronics Conference (IPEC' 83), Tokyo, Japan, 1983.

[4] A. Dell'Aquila and A. Lecci, "A current control for three-phase four-wire shunt active filters," Automatika, vol. 44, no. 3-4, pp. 129-135, 2003.

[5] Z. Y. Zhao, M. Tomizuka, and S. Isaka, "Fuzzy gain scheduling of PID controllers," IEEE Transactions on Systems, Man and Cybernetics, vol. 23, no. 5, pp. 1392-1398, 1993.

[6] P. Viljamaa, Fuzzy gain scheduling and tuning of multivariable fuzzy control methods of fuzzy computing in control systems [Ph.D. thesis], Temper University of Technology, 2000.

[7] G. Dreyfus, J. Martinez, M. Samuelides et al., Réseaux De Neurons: Méthodologie Et Applications, Editions Eyrolles, 2002.

[8] D. Ould Abdeslam, P. Wira, J. Mercklé, Y. A. Chapuis, and D. Flieller, "Stratégie neuromimétique d'identification et de commande d'un filtre actif parallèle,", Revue Des Systèmes, vol. 9, no. 1, pp. 35-64, 2006.

[9] M. Chakphed and P. Suttichai, "Active power filter for threephase four-wire electric systems using neural networks," Electric Power Systems Research, vol. 60, no. 3, pp. 179-192, 2002. 

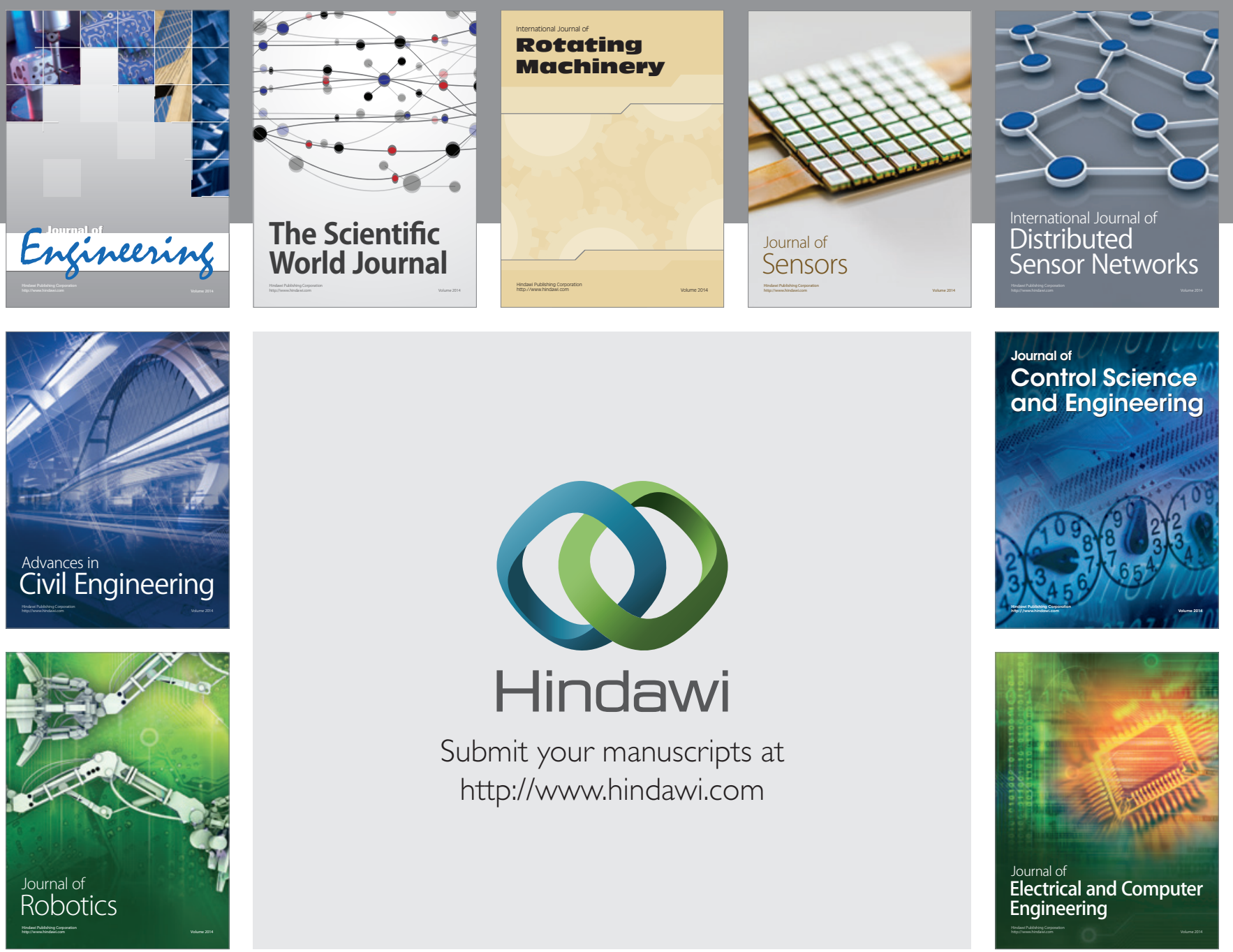

Submit your manuscripts at

http://www.hindawi.com
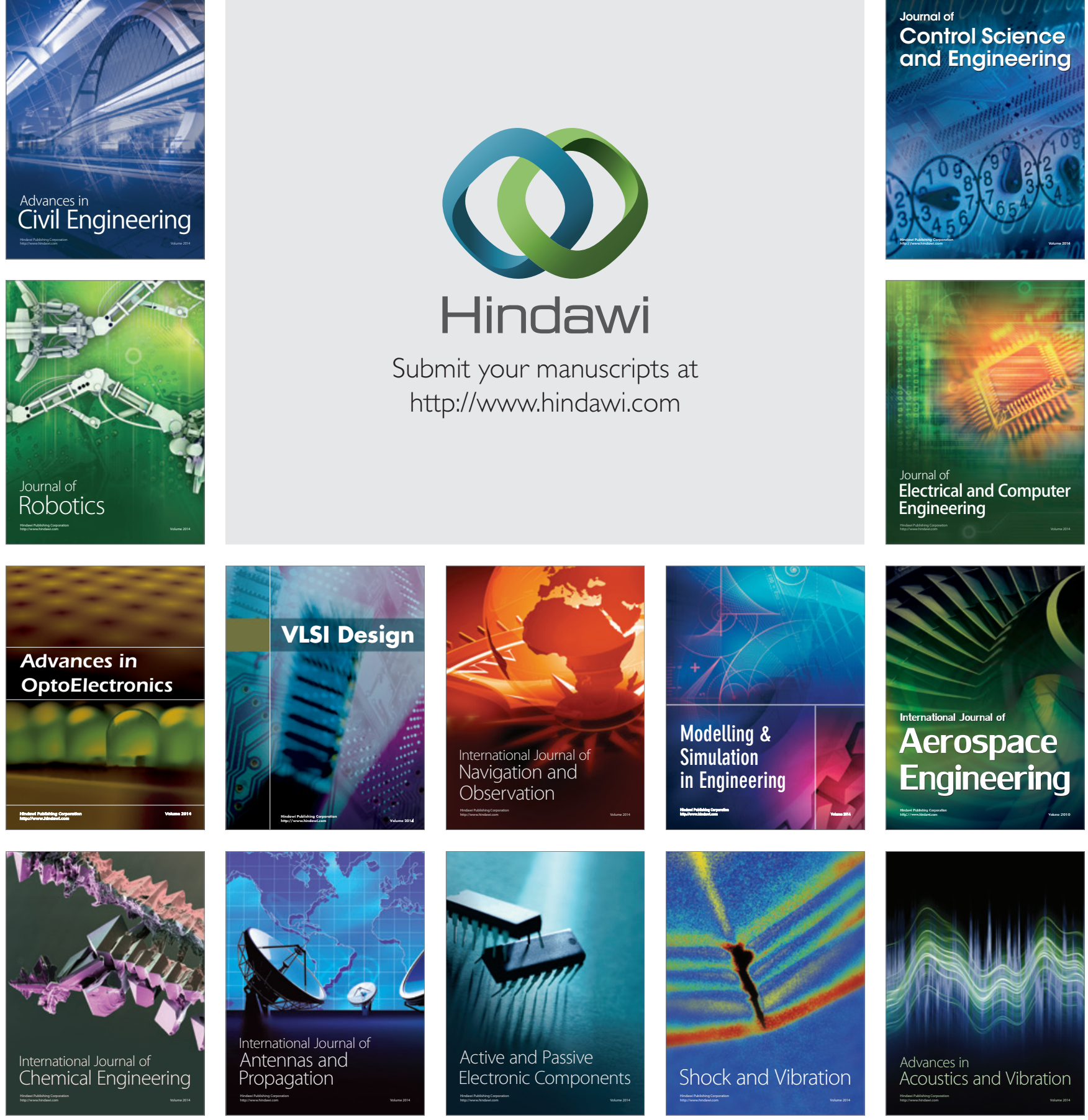